\title{
The Differential Effects of the Quality and Quantity of Online Reviews on Hotel Room Sales
}

Cornell Hospitality Quarterly

2014, Vol. 55(4) 365-375

(C) The Author(s) 2014

Reprints and permissions:

sagepub.com/journalsPermissions.nav

DOI: $10.1177 / 1938965514533419$

cqx.sagepub.com

(SAGE

\author{
Inès Blal' and Michael C. Sturman ${ }^{2}$
}

\begin{abstract}
While it is generally accepted that hotel reviews and ratings posted on travel websites drive hotel sales and revenue, the effects of reviews can be parsed into volume (the number of reviews about a hotel) and valence (the ratings in those reviews). This study finds that the two chief aspects of reviews - volume and valence-have different effects on hotels in various chain scale segments. Industry reports and academic studies show that online reviews influence customers' choice of hotel and thus drive hotels' revenue per available room (RevPAR). However, the valence of those reviews has a greater effect on luxury hotels' RevPAR, while the volume of reviews has a greater effect on lower-tier hotels. Based on a study of 319 hotels in the London metropolitan market, these effects apply equally to urban and suburban hotels, as well as chain and independent hotels. The results further indicate that the rating score effect on RevPAR has little impact on the economy and midscale segments, while an increasing number of reviews actually has negative effects on higher-end hotels.
\end{abstract}

\section{Keywords}

eWOM; sales performance; industry segments

Electronic word-of-mouth (eWOM) has exploded in recent years to include blogs, networks, chat rooms, online reviews, and user-generated websites - all of which have become major components of consumers' marketing and communication decisions (Anderson 2012; Dev, Buschman, and Bowen 2010; Fader and Winer 2012; Wilson, Murphy, and Cambra-Fierro 2012). Industry research reports indicate that online reviews are highly trusted sources of information, second only to friends and family, and are more trusted than traditional media (Nielsen 2012). Ultimately, eWOM reviews have a strong influence in consumer choices when purchasing products or services (Noone and McGuire 2013a, 2013b).

The topic of eWOM in the hotel industry has garnered significant practitioner (Offut and Schetzina 2012; Schetzina and Jain 2012) and academic attention (Anderson 2012; Litvin, Goldsmith, and Pan 2008; Gretzel and Yoo, 2008; Melian-Gonzalez, Buchland-Gidumal, and LopezValcarcel 2013; Ye, Law, Gu, and Chen 2011). Yet, with the exception of a few recent studies (Anderson 2012; Ögüt and Tas 2012; Ye et al. 2011), the conventional wisdom is that eWOM generally affects all hotels' performance. However, as seen elsewhere, the conventional wisdom does not always stand up to empirical scrutiny (e.g., Way, Sturman, and Raab 2010). Furthermore, the specific effects of eWOM are not understood because the construct of eWOM itself includes at least two components, the valence, or customer rating level (Cheung and Thadani 2012; Duan, $\mathrm{Gu}$, and Whinston 2008b), and the volume, or the quantity of discussion about the product (Cheung and Thadani 2012; Duan, $\mathrm{Gu}$, and Whinston 2008b). While many argue that one or both of these aspects of eWOM are critical in predicting sales performance (Chintagunta, Gopinath, and Venkataraman 2010; Dellarocas, Zhang, and Awad 2007), the managerial and academic knowledge of these dimensions remains unclear (Cheung and Thadani 2012; Liu 2006). In short, while many people accept eWOM as a critical component to modern marketing efforts in the hospitality industry, academic research provides little quantitative insight into the importance and effectiveness of eWOM on hotel organizational outcomes.

Further complicating the potential understanding of eWOM's importance in the hotel sector, the industry's complexity itself makes universal statements about eWOM's effects untenable. In this regard, we are speaking of the many categories and subcategories of hotels, the wide range of room rates, and diverse customer types. With so

'Ecole hôtelière de Lausanne, Switzerland

${ }^{2}$ Cornell University, Ithaca, NY, USA

\section{Corresponding Author:}

Inès Blal, Ecole hôtelière de Lausanne, Route de Cojonnex 18, Case Postale 37, 1000 Lausanne 25, Switzerland.

Email: ines.blal@ehl.ch 
many different product types, it seems clear that customers' expectations would also vary widely (Ghose, Ipeirotis, and Li 2012), which makes it unlikely that customer evaluations operate similarly across hotel segments. In that regard, research has often showed that hotel segment is a contextual factor that plays a critical moderating role in consumer behavior (e.g., Zhang, Ye, and Law 2011). So, our effort to understand eWOM begins by delving into key contextual differences within the hospitality industry which may influence the degree to which eWOM affects hotels' revenue per available room (RevPAR).

To test the effects of eWOM on hotels, we examine (1) the effect of TripAdvisor scores, (2) the number of reviews on lodging sales performance, and (3) the moderating effect of the hotel segment on these relationships. Our study both tests the generalizability of prior eWOM research to the hospitality field and expands knowledge about eWOM by providing a more precise test of eWOM's effects by product type.

\section{eWOM and Sales Performance}

As the extension of personal word-of-mouth, eWOM has been extensively studied in such fields as marketing (Fader and Winer 2012; Ghose, Ipeirotis, and Li 2012; Liu 2006), retail (Chevalier and Mayzlin 2006), pricing (Noone and McGuire 2013a, 2013b; Noone, McGuire, and Rohlfs 2011), and information systems (Cheung and Thadani 2012; Gu, Park, and Konana 2012; Mudambi and Schuff 2010). Because eWOM plays a role at the personal level and influences customer behaviors (Ba and Pavlou 2002), researchers have examined the effects of eWOM on firms' sales performance (Duan, Gu, and Whinston 2008a; 2008b; Gu, Park, and Konana 2012; Liu 2006), and some of these studies indicate that eWOM can be used to forecast sales (Dellarocas, Zhang, and Awad 2007; Liu 2006).

To expand on these findings that connect eWOM and sales, we take note of studies that indicate that eWOM has two components (Liu 2006; Mahajan, Muller, and Kerin 1984; Öğüt and Tas 2012). Those elements are the valence, or nature of the review carried (i.e., the degree to which it is positive or negative), and the volume, or quantity of reviews on a particular topic.

The valence of eWOM includes the average numerical ratings found in reviews, the ratio of positive to negative reviews, or the absence or presence of negative reviews on the websites (Chevalier and Mayzlin 2006; Duan, Gu, and Whinston 2008a; Liu 2006; Ye, Law, Gu and Chen 2011). Studies have presented contradictory results about the relationship between eWOM valence and sales performance (Duan, Gu and Whinston 2008b; Liu 2006). Some studies have reported positive significant effects (Chevalier and Mayzlin 2006; Clemons and Gao 2008; Liu 2006; Ye et al. 2011), while others have concluded that the effects of valence on sales performance are non-significant (P. Y. Chen, Wu, and Yoon 2004; Duan, Gu and Whinston 2008a, 2008b; Liu 2006). Another research stream suggests that those contradictory findings could be explained by contextual variables such as market (Chintagunta, Gopinath, and Venkataraman 2010), product type in terms of degree of involvement (Mudambi and Schuff 2010), and whether it is a search or experience product (Gu, Park, and Konana 2012). The volume dimension of eWOM is often quantified as the number of reviews available or the length of the posted reviews (Chevalier and Mayzlin 2006; Duan, Gu, and Whinston 2008a; 2008b; Liu 2006). Studies show a positive association between eWOM volume and sales performance in the movie industry, online sales of books, DVDs, and videos (Y. Chen, Fay, and Wang 2003; Duan, Gu, and Whinston 2008a; 2008b; Liu 2006). For books and movies, the "buzz" created online around the product drives the overall revenues. Research on the dynamics of eWOM in the movie industry shows that eWOM volume is high during the pre-release period and that this activity predicts box office revenues (Liu 2006). Duan, Gu, and Whinston (2008a) further show that the increase in eWOM volume for a popular movie creates a buzz which, in turn, affects the sales.

While we do not expect "buzz" to be a factor in eWOM's effect on hotel sales, this phenomenon relates to the extent of involvement that a customer has in the product, and that certainly is a factor in the hotel industry. In that connection, although the general findings suggest important positive effects associated with eWOM, the substantial differences in hospitality products indicate the need to consider effects particular to the industry. This has not occurred in most eWOM research, which has focused on movies, books, and online retail purveyors, and we see the hotel purchase as being sufficiently different from other products and services that the industry merits its own study. For example, the different degrees of buyer involvement for various hotel types (Akbaba 2006; Barsky and Nash 2003; Gu, Park, and Konana 2012; Suh et al. 1997) affect the role of the online review in the purchase process. In addition, as we said, the "buzz" effect of eWOM observed in the movie and book sales context is of questionable applicability to hotels.

User-generated review websites, such as TripAdvisor, represent the dominant form of eWOM in the lodging industry (Anderson 2012; Ghose, Ipeirotis, and Li 2012; Litvin, Goldsmith, and Pan 2008; O'Connor 2010), although some hotel chains' sites host guest reviews. The 2010 World Travel Market report indicates that 35 percent of users change their choice of hotels after reading online reviews. Thus, we believe eWOM influences hotel sales performance.

Nevertheless, research on the effects of eWOM in hospitality is limited, with three notable exceptions. Öğüt and Tas (2012) and Ye et al. (2011) show that nature of online 
ratings (looking at positive or negative valence) has an impact on online sales. However, they only test eWOM valence and not volume, and their sample is limited to online sales only and not overall sales.

Anderson (2012) examines the effects of several social media dimensions (i.e., position on the search page, Travelocity.com score, number of reviews, and relative hotel price) on the likelihood of purchasing a room via Travelocity. He concludes that both eWOM valence and volume are positively related to the probability of online purchases. He also examines the elasticity of average daily rate (ADR), occupancy, and RevPAR in relation to ReviewPro's (2011) Global Reputation Index (GRI). This study supports the proposition that eWOM influences overall lodging sales and not just online sales.

In this article we build on eWOM research that has indicated important positive effects associated with eWOM in the hospitality industry. Therefore, we presume that favorable eWOM has a generally positive effect for hotels. As we indicated above, our hypotheses consider eWOM volume and valence separately:

Hypothesis 1: eWOM valence is positively associated with sales performance.

Hypothesis 2: eWOM volume is positively associated with sales performance.

\section{Product Type, eWOM, and Sales Performance}

Several studies have shown that the effects eWOM can depend on the characteristics of the product or customer segments (e.g., Chintagunta, Gopinath, and Venkataraman 2010; Gu, Park, and Konana 2012; Mudambi and Schuff 2010). Of particular interest to our study, Zhu and Zhang (2010) test the moderating effects of product and consumer characteristics on the influence of online reviews. They conclude that product and consumer characteristics affect the relationship between online reviews on product sales. Given these findings which indicate that the product type is a key contextual variable in the examination of the impact of eWOM on sales performance, there are several reasons to expect that the effects of eWOM will vary across industry segments. First, researchers have found that relationships vary across hospitality industry segments, including Walsh and Staley (1993) in the area of real estate valuation, O'Neill and Xiao (2006) regarding the effects of brands, and Kosová and Enz (2012) on the effects of crises on room sales. Second, there is evidence that consumers' behavior with respect to eWOM varies across segments. Miguens, Baggio, and Costa (2008), for example, show that customers record more online reviews for higher-end hotels than those in the other segments. Clemons and Gao (2008) compare the online sales effectiveness of properties of three intercontinental brands - upmarket, mid-market, and down-market - and found that the predictors of the effects of ratings on trading up or down vary by segment. These differences in consumer behavior across segments indicate that the influence of eWOM on the purchasing decision could likewise vary. Also, as we indicated above, Anderson (2012) tests the effects of the overall online reputation-measured by ReviewPro's (2011) GRI-on sales performance (ADR, occupancy, and RevPAR). He found diverse effects of reputation, notably, a lower GRI elasticity for the luxury segment compared with other segments. His work presents descriptive statistics that show a difference across segments, but he does not test for its effect on the relationship.

The works by Öğ̈̈t and Tas (2012), Ye et al. (2011), and Anderson (2012) confirm the expected positive effects of eWOM on different types of hotel, particularly for the dimension of valence. For this reason, we investigate the possible moderating effects of the product type (in this case, chain scale segment) on the relationship between eWOM and performance. Based on this discussion, we suggest the following hypotheses:

Hypothesis 3: The effects of eWOM vary across industry segments.

Hypothesis 3a: The effect of eWOM valence varies across industry segments.

Hypothesis 3b: The effect of eWOM volume varies across industry segments.

Having separated volume from valence, there is reason to expect that the moderating effects of eWOM may not operate similarly for these two factors due to the further influence of guest expectations.

As we consider the nature of services provided across various hotel segments, we observe that both the expectations and the importance of service rise as the room price increases (Griffin, Shea, and Weaver 1996; Knutson 1988; Zhang, Ye, and Law 2011) and the customer's tolerance for service failures decreases (e.g., Zeithami, Berry, and Parasuraman 1993). This principle suggests that customer service is less important at lower price segments (Zhang, Ye, and Law 2011), and customers have more tolerance for fluctuations in service (Zeithami, Berry, and Parasuraman 1993). Likewise, customer expectations differ by segment. In economy hotels, value for money, consistent accommodation standards, hygiene and cleanliness are the most important factors for customers (Brotherton 2004). Whereas Midscale customers put a greater emphasis on location, and luxury consumers rate location and service quality as the first key factors (Zhang, Ye, and Law 2011). It is easier for prospective hotel guests to assess factors such as room standards and location themselves, while they often depend on others' experiences, as expressed by eWOM ratings, to estimate the service quality. As we have seen that service 
quality expectations rise as room rates increase with the segment, the importance of the nature of the review on the purchasing decision should increase. We therefore formulate our fourth hypothesis:

Hypothesis 4: The effect of eWOM valence is positively related to industry segment price.

The situation is different in lower-end segments, where standards vary more widely and confidence in the basic level of expected service becomes more critical (Zeithami, Berry, and Parasuraman 1993; Zhang, Ye, and Law 2011). In this case, potential buyers need confirmation that the room is as advertised. For that purpose, they rely on the number of prior experiences, or eWOM volume. We expect volume to be more important at lower-end segments than higher-end segments. We therefore hypothesize the following:

Hypothesis 5: The effect of eWOM volume is negatively related to industry segment price.

In this study, the product type is the six lodging segments determined by Smith Travel Research (STR): economy, midscale, upper midscale, upscale, upper upscale, and luxury. Thus, we examine the overall effect of eWOM on hotels and test the possible moderating effects of the industry segments on the dimensions of eWOM.

\section{Method}

\section{Sample and Data}

We drew data from 319 hotels in the London market over a twenty-six-week period from May 4 to November 30, 2011. We used independent variables from the first thirteen-week period to predict dependent variables in the second thirteenweek period. The $n$ for each market segment was as follows: economy, 67; midscale, 18; upper midscale, 42; upscale, 78; upper upscale, 66; and luxury, 48.

The dependent variable in our hypotheses is sales performance, which was based on measures of RevPAR during the second thirteen-week period, calculated using daily room sales and rooms available provided by STR Global.

The independent variables for our study are the two dimensions of eWOM, based on user-generated content on TripAdvisor. For eWOM valence, we calculated the mean for the online score supplied by TripAdvisor for each property as the score appeared on each Wednesday of the first thirteen-week period. The volume was calculated from the number of reviews posted on TripAdvisor during those thirteen weeks. STR Global matched the eWOM data to the specific hotels in their data set.

STR Global's categorization of market segment is based on a property's ADR. For our market segment analysis, we coded the economy segment as 0 and then coded the rest of the segments from 1 to 5 in ascending order of ADR. We did not include resorts, which we consider to be a special case. To help rule out potential alternative explanations for any effects that we observed, we controlled for hotel size, location, occupancy, whether the hotel held a franchise, and whether it was run by a management company.

To code for hotel size, we assigned numbers as follows: $1=$ fewer than 75 rooms, $2=75-149$ rooms, $3=150-299$ rooms, $4=300-500$ rooms, and $5=$ more than 500 rooms. As was the case in matching ratings to hotel data, STR Global did not provide the specific number of hotel rooms for any property to help ensure the confidentiality of the data. Instead, they determined the categorization based on their assessment of appropriate thresholds and categories of hotels. Although categorization of the data does attenuate the effects associated with this variable (Aguinis, Pierce, and Culpepper 2009), this was a necessary precondition for having access to the data. Nevertheless, given that we measured size using five categories, that our dependent variable is continuous, and that our sample size is substantial, the potential attenuating effects were minimal (i.e., changing correlations by less than .05, see Aguinis, Pierce, and Culpepper 2009).

For the categorical variables, we coded Location as 1 if the hotel was in a suburban location and 0 if in an urban location. We dropped hotels in other locations from our data set. We coded Franchise as 1 if the hotel was affiliated to a brand through a franchise contract, otherwise as 0 . We coded Independent as 1 if the hotel was an independent hotel and 0 if it was affiliated with a brand.

We also controlled for hotel occupancy to help rule out alternative explanations to our findings, as occupancy can play an important role in determining hotel rates due to revenue management strategies (Anderson and Xie 2010; Cross, Higbie, and Cross 2009; Weatherford 1995).

\section{Analyses}

To test our hypotheses, we employed hierarchical linear modeling (HLM; Raudenbush and Bryk 2002). This analytical approach is ideal for our research question because individual hotels are strictly nested within industry segments. HLM allows us to examine whether group membership (in this case, each industry segment) influences relationships associated with independent item-level variables. In addition, we can test whether and how the relationships vary by segment. As described next, we apply four different models to implement this procedure and to test our hypotheses (Hofmann 1997; Raudenbush and Bryk 2002).

Null model. The first step in HLM involves partitioning variance in hotel performance into its within-group and across-group components (Hofmann 1997). This requires a 
one-way analysis of variance examining the amount of variance at both the hotel level (referred to as Level 1) and segment level (referred to as Level 2). The specific model is as follows:

$$
\begin{gathered}
\text { Level 1: } \text { Performance }{ }_{H S}=B_{0 S}+\operatorname{error}(1), \\
\text { Level 2: } B_{0 S}=\gamma_{00}+\operatorname{error}(2) .
\end{gathered}
$$

In this null model, $H$ represents the specific hotel and $S$ represents the segment. By examining the variance of error(2), we can determine whether indeed there is variance across segments. It also allows us to calculate the proportion of variance that exists across segments.

Null model with control variables. The second model extends the first model by adding the control variables to Equation 1. While this model is not a required step to demonstrate the appropriateness of HLM (cf. Hofmann 1997; Raudenbush and Bryk 2002), it helps demonstrate the extent to which our variables of interest (valence, volume, and segment) explain variance in RevPAR beyond that which can be explained by our control variables. For this model, the Level 1 equation thus becomes

Level 1: Performance ${ }_{H S}=B_{0 S}+B_{1-5}($ Control Variables $)$

$$
+\operatorname{error}(1) \text {. }
$$

Note that the size and occupancy control variables were group-mean centered (Hofmann and Gavin 1998).

Random coefficient regression model. The third model we run is a random coefficient regression model. The specific model is as follows:

$$
\begin{aligned}
& \text { Level 1: Performance }{ }_{H S}=B_{0 S}+B_{1 S}(\text { Valence }) \\
& +B_{2 S} \text { (Volume) } \\
& +B_{3-7} \text { (Control Variables) } \\
& +\operatorname{error}(1) \text {, } \\
& \text { Level 2: } B_{0 S}=\gamma_{00}+\operatorname{error}(2 \mathrm{a}) \text {, } \\
& B_{1 S}=\gamma_{10}+\operatorname{error}(2 \mathrm{~b}) \text {, } \\
& B_{2 S}=\gamma_{20}+\operatorname{error}(2 \mathrm{c}) \text {. }
\end{aligned}
$$

For this model, we examine whether the effects of valence and volume vary across groups by examining the amount of error variance in error(2b) and error(2c). Because we are primarily interested in testing whether the effects of valence and volume vary by segment, we groupmean centered the valence and volume variables (Hofmann and Gavin 1998). We used this model to test whether there is significant across-group variance in the effects of valence (Hypothesis 3a) and volume (Hypothesis 3b).
Slopes-as-outcomes model. For the final model, we examine the extent to which a hotel's segment could explain variance in the Level 2 models. We are interested in determining whether there are differences in the within-group slopes, to indicate the extent to which the effects of valence and volume change in different segments. To consider this, it is critical to separate these within-group effects from crosslevel interactions (Hofmann and Gavin 1998; Raudenbush and Bryk 2002). This requires us to group-mean center valence and volume and also to control for the average level of valence and volume in the prediction of the intercept (Hofmann and Gavin 1998). The Level 2 equations for our full model are as follows:

$$
\begin{aligned}
& \text { Level 2: } B_{0 S}=\gamma_{00}+\gamma_{01}(\text { Segment })+\gamma_{02}\left(\text { Valence }_{S}\right) \\
& +\gamma_{03}\left(\text { Volume }_{S}\right)+\operatorname{error}(3 \mathrm{a}) \text {, } \\
& B_{1 S}=\gamma_{10}+\gamma_{11}(\text { Segment })+\operatorname{error}(3 b), \\
& B_{2 S}=\gamma_{20}+\gamma_{21} \text { (Segment) }+\operatorname{error}(3 \mathrm{c}) .
\end{aligned}
$$

Note that Valence ${ }_{S}$ and Volume ${ }_{S}$ represent the average level of valence and volume for each segment.

\section{Results}

In general, we found support for Hypothesis 1, as hotel ratings in the first thirteen-week period were reflected in overall stronger RevPAR in the second period. As shown in Exhibit 1, the positive correlation between valence and RevPAR is strong $(r=.49, p<.001)$. However, volume did not have an effect on RevPAR for all hotels, contrary to Hypothesis 2. As also shown in Exhibit 1, the relationship between volume and RevPAR is not significant ( $r=$ $.02, p=.77$ ). We found that valence and volume are positively correlated $(r=.34, p<.001)$. In addition, as we explain below, valence and volume had differential effects for various hotel segments, as we proposed in Hypothesis 3.

Results of the HLM models are reported in Exhibits 2 and 3. Exhibit 2 presents the estimates of the model coefficients; Exhibit 3 presents the variance components estimated for the models.

Initial HLM results suggest that a multilevel approach is appropriate. The null model shows significant within-group and across-group variance $(67 \%$ of the variance in RevPAR is due to across-group factors, while the remaining $33 \%$ of the variance is due to within-group factors). The amount of across-group variance is clearly significant $(p<.001)$, which supports the examination of the results of our more sophisticated models. The null model with control variables helps explain some variance in RevPAR (7\% of Level 2 variance and $4 \%$ of Level 1 variance) but also reveals that there is still significant Level 2 variance unexplained $(p<$ .001 ), which justifies the application of the third model. At this stage, preliminary results are consistent with practice 
Exhibit 1:

Summary Statistics $(N=319)$.

\begin{tabular}{|c|c|c|c|c|c|c|c|c|c|c|}
\hline & $M$ & $S D$ & 1 & 2 & 3 & 4 & 5 & 6 & 7 & 8 \\
\hline I. RevPAR & 203.44 & 127.24 & 1.00 & & & & & & & \\
\hline 2. Valence & 3.70 & 0.60 & .49 & 1.00 & & & & & & \\
\hline 3. Volume & 4.27 & 0.98 & .02 & .34 & 1.00 & & & & & \\
\hline 4. Segment & 2.63 & 1.71 & .69 & .51 & .14 & 1.00 & & & & \\
\hline 5. Size & 2.47 & 1.08 & -.05 & .07 & .66 & .11 & 1.00 & & & \\
\hline 6. Location & 0.34 & 0.47 & -.25 & -.20 & -.17 & -.23 & -.16 & 1.00 & & \\
\hline 7. Franchise & 0.26 & 0.44 & -.27 & -.34 & -.09 & -.28 & -.06 & .21 & 1.00 & \\
\hline 8. Independent & 0.19 & 0.39 & .33 & .18 & -.11 & .35 & -.17 & -.09 & -.28 & 1.00 \\
\hline 9. Occupancy & 0.88 & 0.068 & -.30 & -.29 & .10 & -.54 & .00 & .04 & .14 & -.26 \\
\hline
\end{tabular}

Note. Coefficients with an absolute value greater than. $\mathrm{II}$ are significant at $p<.05$. RevPAR $=$ revenue per available room.

Exhibit 2:

Coefficient Estimates from Hierarchical Linear Models $(N=319)$.

\begin{tabular}{|c|c|c|c|c|}
\hline & Null Model & $\begin{array}{l}\text { Null Model with } \\
\text { Control Variables }\end{array}$ & $\begin{array}{l}\text { Random Coefficient } \\
\text { Regression Models }\end{array}$ & $\begin{array}{c}\text { Slopes-as- } \\
\text { Outcomes Model }\end{array}$ \\
\hline \multicolumn{5}{|l|}{ Intercept } \\
\hline Intercept & $199.14(42.95)^{* *}$ & $205.59(45.7 \mathrm{I})^{\text {** }}$ & $202.5 \mathrm{I}(46.6 \mathrm{I})^{* *}$ & $205.32(19.00)^{* * *}$ \\
\hline Segment & & & & $-0.63(7.06)$ \\
\hline Mean valence & & & & $0.99(0.12)^{*}$ \\
\hline Mean volume & & & & $-0.056(0.17)$ \\
\hline Size & & $-7.19(4.45)$ & $0.28(5.56)$ & $0.53(5.67)$ \\
\hline Location & & $-28.26(9.83) * *$ & $-24.38(9.23)^{* * *}$ & $-25.73(9.33)^{* *}$ \\
\hline Franchise & & 3.79 (11.91) & $12.01(11.54)$ & $9.50(11.10)$ \\
\hline Independent & & $12.03(12.86)$ & $9.64(12.14)$ & $9.75(12.31)$ \\
\hline Occupancy & & 195.75 (77.77)* & $182.96(75.07)^{*}$ & I $83.68(76.20)^{*}$ \\
\hline \multicolumn{5}{|l|}{ Valence } \\
\hline Intercept & & & $46.67(17.07)^{*}$ & $9.08(15.16)$ \\
\hline Segment & & & & $16.17(5.37)^{*}$ \\
\hline \multicolumn{5}{|l|}{ Volume } \\
\hline Intercept & & & $-0.09(0.12)$ & $0.18(0.15)$ \\
\hline Segment & & & & $-0.11(0.045)^{*}$ \\
\hline
\end{tabular}

Note. Size and occupancy were group-mean centered in various models.

$*_{p}<.05$. **p $<.01$.

and theory, in that we found that suburban hotels have lower RevPAR than urban hotels $(B=-28.26, p<.01)$ and higher occupancy is associated with higher $\operatorname{RevPAR}(B=195.75$, $p<.05$ ), as one would expect.

The third model, the random coefficient regression model, provides mixed support for the first set of hypotheses, as we mentioned above. Hypothesis 1, which predicts that valence is positively associated with sales performance (RevPAR), is supported $(B=46.67, p<.05)$. The effect of volume, however, is not significantly related to $\operatorname{RevPAR}(p=.51)$, contrary to Hypothesis 2 .

The third model also tests whether there is significant variance in the effects of valence and volume by segment. Here the results support both Hypotheses 3a and 3b, as we found significant variance in the effects of both valence and volume (both at $p<.05$ ). Simply put, segment type moderates the relationship between eWOM and sales performance. As we explain further below, depending on a hotel's segment, its sales performance (measured in terms of RevPAR) would be more or less sensitive to the score and the number of reviews.

The final slopes-as-outcomes model seeks to determine whether segment could explain some of the variability within groups. Results support Hypotheses 4 and 5 on the degree and direction of the relationship between eWOM and industry segment. We see that the effect of valence is positively related to segment $(B=16.17, p<.05)$, whereas the effect of volume is negatively related to segment $(B=$ $-0.11, p<.05)$. These data show that the impact of 


\section{Exhibit 3:}

\section{Variance Components $(N=319)$.}

\begin{tabular}{|c|c|c|c|c|c|}
\hline Random Effect & Variance Component & $d f$ & $\chi^{2}$ & $p$ Value & $\%$ Variance Explained \\
\hline \multicolumn{6}{|l|}{ Null model } \\
\hline Intercept & $13,084.14$ & 5 & 493.34 & $<.001 * * *$ & - \\
\hline Level I variance & $6,391.04$ & & & & - \\
\hline \multicolumn{6}{|c|}{ Null model with control variables } \\
\hline Intercept & $12,227.92$ & 5 & 475.53 & $<.001^{* * * *}$ & 6.5 \\
\hline Level I variance & $6,134.46$ & & & & 4 \\
\hline \multicolumn{6}{|c|}{ Random coefficient regression model } \\
\hline Intercept & $12,753.65$ & 5 & 562.46 & $<.001$ & 2.5 \\
\hline Slope for valence & $1,245.66$ & 5 & 12.12 & $.033^{*}$ & - \\
\hline Slope for volume & 0.054 & 5 & 13.27 & $.021 *$ & - \\
\hline Level I variance & $5,401.28$ & & & & 15 \\
\hline \multicolumn{6}{|c|}{ Slopes-as-outcomes model } \\
\hline Intercept & 0.44 & 2 & 0.041 & $>.500$ & 99.9 \\
\hline Slope for valence & 103.14 & 4 & 2.39 & $>.500$ & 92 \\
\hline Slope for volume & 0.012 & 4 & 5.63 & .228 & 78 \\
\hline Level I variance & $5,441.58$ & & & & 15 \\
\hline
\end{tabular}

Note. Percent variance explained for the intercept and Level I variance is in comparison with the null model. Percent variance explained for the slopes of valence and volume is in comparison with the random slopes model. $* p<.05 . * * *_{p}<.001$.

reviewers' scores on performance is greater for higher-end hotels than for lower-end hotels, while the effects of eWOM volume on sales performance across segments are in the opposite direction.

Interestingly, in the final model, the intercepts for valence and volume are both non-significant. This suggests that there is no effect of valence or volume on RevPAR for economy hotels. It was possible, though, that this was an artifact of our need to represent segment as a linear effect (there is insufficient power to fit a model using dummy variables to represent each of the segments). We therefore created a residual file from the random coefficient regression models (Model 3), which provides an estimate of the estimated coefficients for both valence and volume for each segment.

While we cannot perform specific significance tests on these coefficients, the pattern of results is generally consistent with the hypotheses, as shown in Exhibit 4. The effects of valence are positive but weakest for economy hotels (19.59) and become consistently stronger as we move up the segments, with the largest effect being in luxury hotels (111.32). It is also worth noting that the effect of valence in luxury hotels is almost double the effect of upper upscale hotels, which have an estimated effect of 59.21.

The effect of volume appears to be positive for economy hotels $(B=0.09)$ and it is also positive for midscale $(B=$ $0.08)$ and upper midscale $(B=0.05)$. However, the volume effect turns negative for upscale and luxury hotels. With $\mathrm{B}=-0.51$, the luxury value is over three times the effect for upper upscale hotels.

\section{Exhibit 4:}

Valence and Volume Estimates from Random Coefficient Regression Model $(N=319)$.

\begin{tabular}{lcc}
\hline Segment & $\begin{array}{c}\text { Estimated } \\
\text { Coefficient for } \\
\text { Valence (i.e., Score) }\end{array}$ & $\begin{array}{c}\text { Estimated Coefficient } \\
\text { for Volume (i.e., } \\
\text { Number of Reviews) }\end{array}$ \\
\hline Economy & 19.59 & 0.09 \\
Midscale & 21.63 & 0.08 \\
Upper midscale & 26.05 & 0.05 \\
Upscale & 40.99 & -0.05 \\
Upper upscale & 59.21 & -0.17 \\
Luxury & 111.32 & -0.51 \\
\hline
\end{tabular}

Note. Segment $n$, as follows: economy: 67 ; midscale: 18; upper midscale: 42; upscale: 78; upper upscale: 66; luxury: 48.

\section{Discussion and Managerial Implications}

Our findings (illustrated in Exhibit 5) underscore the importance of management attention to user-generated online content, notably on TripAdvisor. This study goes beyond prior work by demonstrating the relative magnitude of the effects of online ratings for various hotel chain scale segments. It is important to note that ratings have a greater effect on upper-tier hotels, while volume of reviews drives the lower-tier hotels' results. Moreover, it is critical to note that these conclusions apply to independent hotels, franchised hotels, and properties operated by international chains. 


\section{Exhibit 5:}

Effects of Valence and Volume by Industry Segment $(N=319)$.

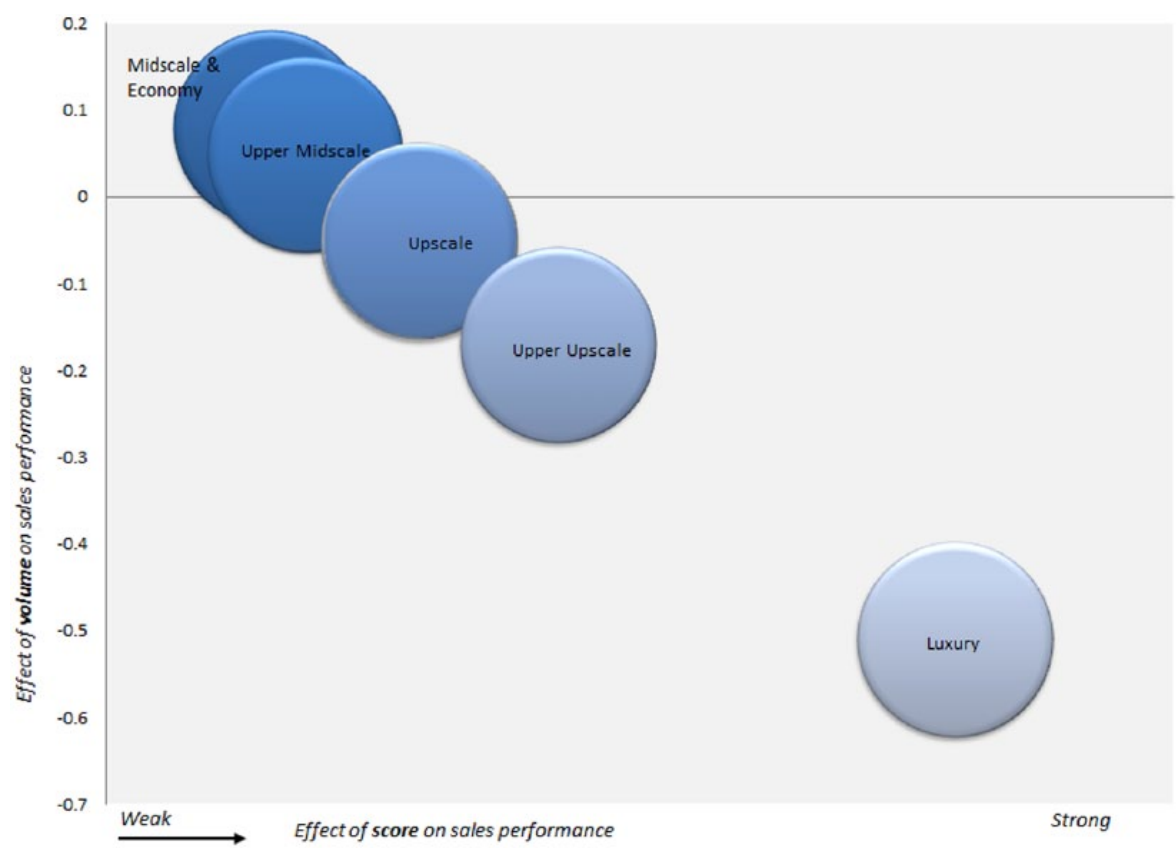

Our results indicate that the ideal for luxury properties would be a limited number of highly positive ratings. Managers may wish to focus on actions that address guest concerns and eventually increase the review scores for their hotels without necessarily aiming for a high number of reviews. Given that scarcity and exclusivity are associated with status in the hotel industry (Catrett and Lynn 1999), it may be that having numerous reviews becomes a signal that the particular hotel's experience is not associated with exclusivity. Quite clearly, luxury properties' sales benefit more from a higher score than from a large number of reviews. Managers would therefore do well to focus on guest satisfaction rather than the number of online reviews.

The pattern is similar for upper upscale and upscale hotels, but the magnitude of the effects is notably smaller than for luxury hotels. Our study shows that just like luxury hotels, a higher score boosts upscale hotels' sales performance, while more reviews hinder it. However, the negative implications of more reviews are notably smaller for upper upscale hotels than luxury hotels, and it is nearly zero for upscale hotels. Managers of these properties may not benefit from higher response rates, but they likely do not need to worry extensively over necessarily getting too many.

While upper-tier managers might struggle with ways to achieve higher guest ratings, for managers of economy, midscale, and upper midscale hotels, the way is clear for improving sales performance by increasing the number of reviews. Managers of these properties can boost the positive effect of a good score with a higher number of online reviews.

\section{Contribution and Future Research}

Our research confirms that contextual factors such as product type (in this case, hotel segments) should be taken into consideration when examining the question of the effects of eWOM on sales performance. Our findings support the argument that the hospitality industry involves specific contextual settings for studying eWOM. While research on movies, DVDs, and books highlights the positive impact of eWOM volume on sales performance, this research reveals that volume is not the only factor. Indeed, the "buzz effect" of a high volume of comments does not apply to high-end hotel properties or perhaps to any hotel at all. Our results also indicate that moderating effects of product type is different for valence as well. While all hotels benefit from positive reviews, the importance of high scores is greatest for upper-tier hotels. To our knowledge, ours is the first study that explores the role of eWOM valence and volume on sales performance from this perspective.

Our study's limitations temper the generalizability of our findings but also present opportunities for future research. Perhaps the greatest limitation is that we drew our sample from a single market to help control for the 
effects of differential destination attractiveness. Future research could test whether our results hold in different geographic markets. Our finding of negative effects for volume in the luxury segment (after controlling for the level of valence) is both interesting and surprising. It would be highly valuable to see whether this effect replicates in other markets.

It could also be useful to further explore the potential moderating effects of product type in leisure and business markets. The reliance on a larger sample, with data from other locations, could also strengthen the generalizability of our findings.

In the hospitality industry, it would also be valuable to both branded operators and hotel owners to know whether the positive effect of eWOM volume affects the brand itself as it does property performance. Future studies could examine whether a "buzz effect" exists for the brands and whether that effect varies across segments. Exploring these avenues would help academics develop a deeper understanding of the construct of eWOM. As for branded hotel operators and hotel owners, they would benefit from guidelines to manage the daunting issue of online presence.

With this confirmation of the moderating effect of product type on the effects of eWOM on sales performance in the hospitality industry, it would be interesting to test whether luxury items generally present the same patterns. This knowledge would complement our understanding on the effects of eWOM on organizational outcomes, particularly relating to the influence of perceptions of exclusivity on purchase of luxury products.

Yet even with these limitations, our work represents an important step in research on eWOM. By examining valence and volume simultaneously, we demonstrate that these two dimensions of eWOM, although correlated, have distinct effects on sales performance, and furthermore, the nature of the product under consideration moderates these effects. Given that we found one set of moderating effects, one may infer that the impact of eWOM also may depend on other factors. Thus, future research on eWOM should consider other potential moderating effects.

In the end, our use of eWOM data from one time period to predict outcomes in a subsequent time period provides strong support for the conclusion that eWOM indeed has organizational-level effects. In general, this research confirms the importance and complexity of eWOM and its relationships. Specific to hospitality, our findings show that, when it comes to online reviews, both quantity and quality matter, but the extent and even the nature of the effects depend on the characteristics of the hotel product being considered.

\section{Declaration of Conflicting Interests}

The author(s) declared no potential conflicts of interest with respect to the research, authorship, or publication of this article.

\section{Funding}

The author(s) disclosed receipt of the following financial support for the research, authorship, or publication of this article: The work described in this article was supported by a grant funded by the HES-SO, University of Applied Sciences and Arts- Western Switzerland -RCSO Economy and Business (Project number: 34072/ES-ECOMGT 13-06).

\section{References}

Aguinis, H., C. A. Pierce, and S. A. Culpepper. 2009. Scale coarseness as a methodological artifact correcting correlation coefficients attenuated from using coarse scales. Organizational Research Methods 12 (4): 623-52.

Akbaba, A. 2006. Measuring service quality in the hotel industry: A study in a business hotel in Turkey. International Journal of Hospitality Management 25 (2): 170-92.

Anderson, C. K. 2012. The impact of social media on lodging performance. Center for Hospitality Research Report 12 (15). https://www.hotelschool.cornell.edu/research/chr/pubs/ reports/abstract-16421.html (Accessed January 12, 2013).

Anderson, C. K., and X. Xie. 2010. Improving hospitality industry sales: Twenty-five years of revenue management. Cornell Hospitality Quarterly 51 (1): 53-67.

Ba, S., and P. A. Pavlou. 2002. Evidence of the effect of trust building technology in electronic markets: Price premiums and buyer behavior. MIS Quarterly 26 (3): 243-68.

Barsky, J., and L. Nash. 2003. Customer satisfaction applying concepts to industry-wide measures. Cornell Hotel and Restaurant Administration Quarterly 44 (5-6): 173-83.

Brotherton, B. 2004. Critical success factors in UK budget hotel operations. International Journal of Operations \& Production Management 24 (9): 944-69.

Catrett, J., and M. Lynn. 1999. Managing status in the hotel industry. Cornell Hotel and Restaurant Administration Quarterly 40 (1): 26-39.

Chen, P. Y., S. Y. Wu, and J. Yoon. 2004. The impact of online recommendations and consumer feedback on sales. Proceedings of ICIS 2004 International Conference on Information Systems, Seattle, WA, December, 711-24. http://aisel.aisnet. org/icis2004/58 (accessed March 12, 2013).

Chen, Y., S. Fay, and Q. Wang. 2003. Marketing implications of online consumer product reviews. Working paper, department of marketing, University of Florida. http://plaza.ufl.edu/faysa/ review.pdf. .

Cheung, C. M. K., and D. R. Thadani. 2012. The impact of electronic word-of-mouth communication: A literature analysis and integrative model. Decision Support Systems 54 (1): 461-70.

Chevalier, J. A., and D. Mayzlin. 2006. The effect of word of mouth on sales: Online book reviews. Journal of Marketing Research 43 (3): 345-54.

Chintagunta, P. K., S. Gopinath, and S. Venkataraman. 2010 The effects of online user reviews on movie box office performance: Accounting for sequential rollout and aggregation across local markets. Marketing Science 29 (5): 944-59.

Clemons, E. K., and G. G. Gao. 2008. Consumer informedness and diverse consumer purchasing behaviors: Traditional mass-market, trading down, and trading out into the long tail. Electronic Commerce Research and Applications 7 (1): 3-17. 
Cross, R. G., J. Higbie, and D. Q. Cross. 2009. Revenue management's renaissance: A rebirth of the art and science of profitable revenue generation. Cornell Hospitality Quarterly 50 (1): 55-61.

Dellarocas, C., X. Zhang, and N. F. Awad. 2007. Exploring the value of online product reviews in forecasting sales: The case of motion pictures. Journal of Interactive Marketing 21 (4): 23-45.

Dev, C., J. D. Buschman, and J. T. Bowen. 2010. Hospitality marketing: A retrospective analysis (1960-2010) and predictions (2010-2020). Cornell Hospitality Quarterly 51 (4): 459-69.

Duan, W., B. Gu, and A. B. Whinston. 2008a. Do online reviews matter?-An empirical investigation of panel data. Decision Support Systems 45 (4): 1007-16.

Duan, W., B. Gu, and A. B. Whinston. 2008b. The dynamics of online word-of-mouth and product sales: An empirical investigation in the movie industry. Journal of Retailing 84 (2): 233-42.

Fader, P. S., and R. S. Winer. 2012. Introduction to the special issue on the emergence and impact of user-generated content. Marketing Science 31 (3): 369-71.

Ghose, A., P. G. Ipeirotis, and B. Li. 2012. Designing ranking systems for hotels on travel search engines by mining usergenerated and crowdsourced content. Marketing Science 31 (3): 493-520.

Gretzel, U., and K. H. Yoo. 2008. Use and impact of online travel reviews. In Information and communication technologies in tourism, ed. P. O'Connor, W. Höpken, and U. Gretzel, 35-46. New York: Springer-Verlag.

Griffin, R. K., L. Shea, and P. Weaver. 1996. How business travelers discriminate between mid-priced and luxury hotels: An analysis using a longitudinal sample. Journal of Hospitality \& Leisure Marketing 4 (2): 63-75.

Gu, B., J. Park, and P. Konana. 2012. The impact of external word-of-mouth sources on retailer sales of high-involvement products. Information Systems Research 23 (1): 182-96.

Hofmann, D. A. 1997. An overview of the logic and rationale of hierarchical linear models. Journal of Management 23 (6): 723-44.

Hofmann, D. A., and M. B. Gavin. 1998. Centering decisions in hierarchical linear models: Implications for research in organizations. Journal of Management 24 (5): 623-41.

Knutson, B. 1988. Frequent travelers: Making them happy and bringing them back. Cornell Hotel and Restaurant Administration Quarterly 29 (1): 83-87.

Kosová, R., and C. A. Enz. 2012. The terrorist attacks of 9/11 and the financial crisis of 2008: The impact of external shocks on US hotel performance. Cornell Hospitality Quarterly 53 (4): 308-25.

Litvin, S. W., R. E. Goldsmith, and B. Pan. 2008. Electronic wordof-mouth in hospitality and tourism management. Tourism Management 29 (3): 458-68.

Liu, Y. 2006. Word of mouth for movies: Its dynamics and impact on box office revenue. Journal of Marketing 70 (3): 74-89.

Mahajan, V., E. Muller, and R. Kerin. 1984. Introduction strategy for new products with positive and negative word-of-mouth. Management Science 30 (12): 1389-404.

Melian-Gonzalez, S., J. Buchland-Gidumal, and B. G. LopezValcarcel. 2013. Online customer reviews of hotels: As participation increases, better evaluation is obtained. Cornell Hospitality Quarterly 53 (4): 274-83.

Miguens, J., R. Baggio, and C. Costa. 2008. Social media and tourism destinations: TripAdvisor case study. Proceedings of IASK Advances in Tourism Research 2008 (ATR 2008), Aveiro, Portugal, May. http://www.uib.es/depart/deeweb/pdi/ acm/arxius/intermediacio tfg/baggio-aveiro2.pdf.

Mudambi, S. M., and D. Schuff. 2010. What makes a helpful online review? A study of customer reviews on Amazon.com. MIS Quarterly 34 (1): 185-200.

Nielsen. 2012. Global consumers' trust in "earned" advertising grows in importance. http://www.nielsen.com/us/en/pressroom/2012/nielsen-global-consumers-trust-in-earned-advertising-grows.html (accessed September 9, 2013).

Noone, B. M., and K. A. McGuire. 2013a. Effects of price and user-generated content on consumers' prepurchase evaluations of variably priced services. Journal of Hospitality \& Tourism Research. Published electronically February 27. doi:10.1177/1096348012461551.

Noone, B. M., and K. A. McGuire. 2013b. Pricing in a social world: The influence of non-price information on hotel choice. Journal of Revenue and Pricing Management 12 (5): 385-401.

Noone, B. M., K. A. McGuire, and K. V. Rohlfs. 2011. Social media meets hotel revenue management: Opportunities, issues and unanswered questions. Journal of Revenue and Pricing Management 10 (4): 293-305.

O'Connor, P. 2010. Managing a hotel's image on TripAdvisor. Journal of Hospitality Marketing \& Management 19 (7): 754-72.

Offut, B., and C. Schetzina. 2012. Travel innovation \& technology trends: 2012 \& beyond-Special report for world travel market. Paper presented at the PhoCusWright Conference, London, UK, November.

Öğüt, H., and B. K. O. Taş. 2012. The influence of internet customer reviews on the online sales and prices in hotel industry. The Service Industries Journal 32 (2): 197-214.

O'Neill, J. W., and Q. Xiao. 2006. The role of brand affiliation in hotel market value. Cornell Hotel and Restaurant Administration Quarterly 47 (3): 210-23.

Raudenbush, S. W., and A. S. Bryk. 2002. Hierarchical linear models: Applications and data analysis methods (2nd ed.). Thousand Oaks: SAGE.

ReviewPro. 2011. A basic guide to managing online reviews for hotels. August 3. http://www.reviewpro.com/basics-managing-online-reviews-hotels-4982 (accessed March 10, 2013).

Schetzina, C., and D. Jain. 2012. PhoCusWright's China online travel traffic overview whitepaper. Paper presented at the PhoCusWright Conference,Scottsdale-Phoenix, Arizona, USA, November.

Suh, S. H., Y. H. Lee, Y. Park, and G. C. Shin. 1997. The impact of consumer involvement on the consumers' perception of service quality-focusing on the Korean hotel industry. Journal of Travel \& Tourism Marketing 6 (2): 33-52.

Walsh, C. B., and H. B. Staley. 1993. Considerations in the valuation of hotels. Appraisal Journal 61:348-56.

Way, S. A., M. C. Sturman, and C. Raab. 2010. What matters more? Contrasting the effects of job satisfaction and service climate on hotel F\&B managers' job performance. Cornell Hospitality Quarterly 51:379-397. 
Weatherford, L. R. 1995. Length of stay heuristics: Do they really make a difference? Cornell Hotel and Restaurant Administration Quarterly 36 (6): 70-79.

Wilson, A., H. Murphy, and J. Cambra Fierro. 2012. Hospitality and travel: The nature and implications of user-generated content. Cornell Hospitality Quarterly 53 (3): 220-28.

World Travel Market. 2010. World travel market 2010 industry report. http://www.wtmlondon.com/files/wtm2010_industry_ report.pdf (accessed March 10, 2013).

Ye, Q., R. Law, B. Gu, and W. Chen. 2011. The influence of user-generated content on traveler behavior: An empirical investigation on the effects of e-word-of-mouth to hotel online bookings. Computers in Human Behavior 27 (2): 634-39.

Zeithami, V. A., L. L. Berry, and A. Parasuraman. 1993. The nature of determinants of customer expectations of service. Journal of the Academy of Marketing Science 21 (1): $1-12$.

Zhang, Z., Q. Ye, and R. Law. 2011. Determinants of hotel room price: An exploration of travelers' hierarchy of accommodation needs. International Journal of Contemporary Hospitality Management 23 (7): 972-81.

Zhu, F., and X. Zhang. 2010. Impact of online consumer reviews on sales: The moderating role of product and consumer characteristics. Journal of Marketing 74 (2): 133-48.

\section{Author Biographies}

Inès Blal (Ph.D., Virginia Polytechnic Institute and State University) is an Assistant-Professor of Strategic Management at the Ecole hotelière de Lausanne, Switzerland. Her current research involves performance measures of lodging corporations and the execution of expansion strategies.

Michael C. Sturman (Ph.D., Cornell University) is a Professor of Management, the Kenneth and Marjorie Blanchard Professor of Human Resources, and the Associate Dean for Faculty Development at Cornell University's School of Hotel Administration. His current research focuses on the prediction of individual job performance over time, the influence of compensation systems, and research methods. 